\title{
COMPLETE TREE MENSURATION ${ }^{1}$
}

\author{
BY HAROLD E. YOUNG 2
}

Oxf. 539

\section{INTRODUCTION}

The complete tree concept is biological and technological investigation of the entire tree from root hairs to leaf hairs inclusive as a prelude to intensive management of selected areas similar to agricultural crops and to utilization similar to the cattle and hog industries in the United States. This has been extended to a complete forest concept to include seedlings, samplings and woody perennials.

I presented the complete tree concept to foresters in a number of European countries during the '63-'64 academic year and would be less than honest if I stated that those who politely listened showed positive interest. Reaction was similar in North America during the first year of my return. During the past two years there has been increased positive response to my lectures on this concept and notable evidence in both basic and applied research that the potential of the complete tree concept is being explored.

Forest biologists can view this simply as the application of ecological interest in primary productivity. Forest technologists can view this simply as the ultimate in utilization. It actually encompasses all of forestry with more drastic changes in thinking than in practices. Despite this apparent revolutionary approach all changes from present forest management and utilization to fulfillment of the complete tree concept are not as extensive as those that have actually taken place in the past 30 years.

In the short time since I first proposed the complete tree concept no one has made a complete tree harvester nor has anyone demonstrated that all of the logging residue can be used. Then why concern ourselves with complete tree mensuration? With the assurance possessed by those who dream while wide awake I am confident that the complete tree concept will be absorbed into our scientific and professional perspectives and therefore we must be prepared to cope with it. It does have quantitative problems particularly with sampling methods. This paper will not be long for complete tree mensuration is in its infancy and by its very simplicity should not lead to textbooks of comparable thickness to those on volume mensuration.

\section{Tree and Shrub Measurement}

With the complete tree concept limited to selected areas there will continue to be extensive natural forest areas for economic, protective and cultural reasons. There will be many reasons for comparing and/or combining information from natural forests and planted forests and this can be accomplished by using the same physical dimensions, diameter and height, for both forests. These do characterize commercial size trees fairly well but we should not rule out the possibilities of better dimensional measurements with improved instrumentation. An unpublished study of trees of seedling

\footnotetext{
${ }^{1}$ Prepared for the Forest Biometry Working Group in Freiburg, Germany, September 1-2, 1967. 2 Professor, School of Forest Resources, University of Maine, Orono, Maine, U.S.A.
} 
and sapling size has demonstrated that height alone can be used to make reliable estimates of the weight of the various components. Height can be used to characterize the general size of woody shrubs but these have multiple stems and height alone might not be adequate. It is likely that height and the number of stems per unit of area encompassed by the woody shrub might be necessary to estimate the weight of the shrub components with reliability.

Breast height diameter measurements are easy to make but this position includes some butt swell, therefore some other point or series of points on the tree bole might be more sensitively related to the weight of the various tree components. Commonly used height measuring instruments may have as much as a four-foot human error. In this era of continuously improving instrumentation a new approach such as the complete tree concept deserves a fresh perspective of tree and stand measuring devices with a view to increasing accuracy and possible reduced measuring time per tree or stand, or as an alternative, increased measuring time per tree for increased accuracy but reduce number of measurements per stand.

\section{Basic Unit of Measurement}

Volume has been the primary unit of measurement for forest products and standing trees for a very long time. In recent years weight has been used increasingly in the USA for measurement of primary products mainly to decrease measurement time and thereby cost and to a lesser degree to eliminate human error. Weight measurement accuracy is affected by the moisture content. This is so variable that until instruments are developed that can quickly and accurately estimate the moisture content, weight cannot be advocated as being more accurate than volume.

In North America we have used cubic volume as calculated by the Smalian and Huber formulae as the basis for estimating errors of measurement that occur when using the board foot or cord units of measurement. The paper that I will present at a section 25 , IUFRO meeting several days hence demonstrates that there may be very large variation between the calculated and displaced volume of a log or bolt. The Smalian and Huber formulae were first approximations and very little has been done to improve them in the past 150 years. If we continue to use volume as a basic unit of measurement in scientific, professional and industrial forestry it will be essential that more accurate methods are developed.

In the complete tree concept every component of the tree is considered. Because of the variety of shapes and sizes of the roots, stump, branches and top it is impossible to consider any of the standard methods of volume determination. Therefore weight must be the basic unit of measure for the entire tree and its several components. In earlier papers I have referred to the roots, stump, bole, etc. as components. Some foresters think of the wood, bark and leaves as components of a tree. In either case weight is the only satisfactory unit of measurement.

Beam scales, strain gauges, etc. can be used to weigh complete trees or tree components with a high degree of accuracy. The variable moisture content of standing trees and freshly cut primary products indicates that fresh weight is a less desirable basic unit of measurement than dry weight. In mature trees the shear size of the components makes it impractical to place 
each in an oven to dry for 24 hours at $105^{\circ}$ centigrade. Thus it is necessary to properly sample each component to determine the moisture content of the wood and bark as a means of reliably estimating the dry weight of wood and bark in the component. Sampling is time consuming and always involves error. Again we must depend on developments in instrumentation to provide more rapid and satisfactory solutions to this vexing problem.

\section{GROWTH AND YIELD}

Implicit within the complete tree concept is research in and use of genetics, fertilizers, irrigation and other management techniques to provide optimum fiber production per unit of area in economic terms. This boldly and baldly involves spending money as a means of increasing profit. Thus the accuracy and rapidity with which growth information can be obtained is of much greater importance in a forest managed within the complete tree concept. Research relating destructive tree sampling with foliar analysis should be the basis for developing foliar analysis as a rapid and sensitive method for evaluating the growth rate of trees and stands as a means of deciding what management practices to introduce.

It is my estimate that by the year 2000 harvesting and processing equipment will be invented and commercially developed so that the primary forest product will be chips from the entire tree. The chips will be further reduced to make paper or paper products or will be reconstituted into shapes and sizes currently sawed or sliced from the round $\log$ as well as a variety of shapes, sizes and forms that cannot now be sawed or sliced from a round log. For such harvesting and processing equipment optimum fiber production per unit of area in economic terms is the only sensible approach.

Optimum fiber production per acre is a drastically different concept than sawtimber or pulpwood production in which minimum tree size is of importance. From the standpoint of fiber production extremely dense stands are not stagnating and a thinned stand would be an economic luxury. Instead of six foot by six foot planting on a 60 year rotation we might find that two foot by two foot planting on a 20 to 25 year rotation might produce the most fiber in an economic sense. As stated earlier implimentation of the complete tree concept requires a major change in perspective and philosophy.

Growth can be determined on a dry weight basis for the complete tree in terms of its components with each component separated into bark and wood when appropriate. This is certainly the least complicated growth determination procedure. It can be used now for ecological purposes and later for practical purposes when harvesting and processing equipment is available for complete tree utilization.

At the present time primary products such as pulpwood, sawlogs, veneer logs, posts, poles and piling do not have the same value per unit of measurement. This does not complicate growth procedures in the complete tree concept providing the various primary products consist of either a single component or a group of components.

Yield is the fiber production per unit of area for complete trees and their components in terms of specific seedling stock and prescribed management techniques. Destructive sampling of complete trees will be necessary to develop yield tables. Sampling at three and five year intervals during the 
life of a plantation may be sufficient to provide information for yield tables with growth information as a by product.

Yield in the complete tree concept is the expectation in terms of fiber production with specific management practices excluding losses that may occur due to insects, disease and fire. I would like to stress the economic implication for there may be considerable difference between maximum and optimum yield. The latter would be the one that would produce the greatest profit in terms of the amount invested.

\section{INVENTORY}

Inventory of land managed under the complete tree concept should be as simple as that of agricultural crop land. Airphotos can be used to delineate different age classes and a minimum amount of sampling should be necessary within a plantation to estimate its weight. Natural stands will be inventoried by modifications of present methods but with better instruments for two purposes. One will be to continue them as natural stands for watershed management, recreation and selective logging for special products. The other will be as a step in changing a natural forest to a planted forest.

Weight tables by species will be necessary for either type of inventory. Weight tables similar in format to volume tables have been prepared for eight species in Maine that estimate the fresh and dry weight of complete trees and their several components in terms of diameter and height for trees of present commercial size. Tables for small trees have been prepared for the same species based on height alone. Tables could be prepared for woody shrubs in terms of height and number of stems.

At the present time inventory methods are based on area in the form of plots or strips. With the extension of $3 \mathrm{p}$ sampling into inventory some area control will be necessary but more emphasis can be placed on individual trees.

\section{Statistical Methods}

The literature on foliar analysis of forest trees is miniscule compared with that of agricultural crops. Examination of reviews of the accomplishments in foliar analysis of fruit trees during the past 30 years indicates the sampling difficulties that they have encountered. We can take advantage of their accumulated experience but will have to develop methods of sampling that will be sufficiently accurate for each species as crown position, age of needles (in the case of conifers) and seasonal variation are factors of considerable importance.

Destructive sampling of complete mature trees may require as much as two man days for field and laboratory analysis for fresh and dry weight with at least that much additional time for preparation of samples for chemical analysis. Better methods than those in use will undoubtedly be developed, however these phases will always be relatively time consuming. Therefore, attention must be paid to the minimum amount of sampling within a tree to properly characterize the tree and between trees to properly characterize a stand growing on a particular site.

The practical accomplishment of statistical analysis will be in relating the 
weight and nutrient element information obtained by time consuming field and laboratory work to easily obtained physical measurements of trees and shrubs including information on the amount of such measurements that must be taken to characterize either a tree or a stand.

\section{Selected References}

DYER, R. F. 1967. A weight, nutrient element and pulping study of northern white cedar, Thuja occidentalis m.s. thesis.

DYER, R. F., A. J. CHASE and H. E. YOUNG. 1967. Pulp from presently non-commercial woody perennials. Pulp Pap. Mag. Can. In press.

YOUNG, H. E., L. STRAND and R. ALTENBERGER. 1964. Preliminary fresh and dry weight tables for seven tree species in Maine. Tech. Bull. No. 12. Maine Agri. Exp. Sta.

YOUNG, H. E, and A. J. CHASE. 1965. Fiber weight and pulping characteristics of the logging residue of seven tree species in Maine. Tech. Bull. No. 17. Maine Agri, Exp. Sta.

YOUNG, H. E., P. CARPENTER and R. ALTENBERGER. 1965. Preliminary tables of some chemical elements for seren tree species in Maine. Tech. Bull. No. 20. Maine Agri. Exp. Sta.

YOUNG, H. E. 1966. World forestry based on the complete tree concept. Proceedings Sixth World Forestry Congress, Madrid, Spain.

YOUNG, H. E. 1967. The challenge of complete tree utilization. Annual meeting of Forest Products Research Society, July 5, 1967, Vancouver, B.C., Canada.

YOUNG, H. E., W. C. ROBBINS and S. WILSON. Errors in volume determination of primary forest products. Fourteenth World Congress of International Union of Forestry Research Organizations, Section 25, Munich, Germany, September, 1967. 